do con la señal de la Corte y la del marcador Juan de Orea, quien desempeñó el cargo de marcador de Corte entre 1677 y $1694{ }^{34}$, parece lógico deducir que está bacía se labró en Madrid, en el transcurso del último cuarto del siglo xvil, y probablemente por el mismo desconocido platero, quien en este trabajo dejó constancia de su competencia.

Por otra parte, cabe imaginar, también, que la versión americana de bacía avenerada está inspirada en ejemplares peninsulares.

El estudio de este conjunto de piezas nos permite enriquecer nuestro conocimiento de la platería civil española del siglo xvII y, a la vez, ilustra la evolución estética que tuvo lugar en dicha centuria. El jarro y la fuente reflejan el gusto, deudor del clasicismo, que imperaba en los primeros decenios del siglo; por su parte el taller responde a un trabajo de transición en el que se incorporan ya elementos barrocos, pero es en la bacía donde la estética barroca aparece ya plenamente asimilada.

Asunción de Orbe y SivatTe

\title{
JUAN SOREDA Y LAS TABLAS DEL ANTIGUO RETABLO DE LUZÓN (GUADALAJARA) ${ }^{1}$
}

En el presente artículo se da noticia del hallazgo en la iglesia de Torremocha del Pinar (Guadalajara), de la obra documentada más antigua de Juan Soreda ${ }^{2}$ : el retablo mayor de Luzón ${ }^{3}$. Todo lo referente al modo en que las cinco tablas llegaron desde Luzón hasta la citada localidad de Torremocha del Pinar se tratará más adelante; por el momento he de señalar que tras este descubrimiento es posible construir con mayor solidez la etapa temprana de Juan Soreda ${ }^{4}$. Las cinco escenas que se dan a conocer son inéditas y en ellas se aprecia que Soreda es,

${ }^{34}$ J. M. Cruz Valdovinos: «Platería», p. 591.

1 Quiero expresar mi agradecimiento a don J. Rogelio Buendía por su experta dirección y por su ánimo continuo, sin los que mis investigaciones sobre Soreda y la pintura seguntina del siglo Xvı no hubieran salido adelante.

${ }^{2}$ Hasta ahora se consideraba, correctamente a la luz de los datos que se tenían, que sus obras conservadas más antiguas eran las tablas de la Virgen con el Niño del Museo Catedralicio de El Burgo de Osma (Soria), la Presentación en el Templo de San Pedro de Soria y la Virgen con el Niño del Museo de Dijon. ÁVILA, A., «El pintor Juan Soreda. Estudio de su obra», Goya, 1979, pp. 137-138.

${ }^{3}$ Bibliografía sobre Soreda: Pérez Villamil, M., La catedral de Sigüenza, Madrid, 1899, pp. 171, $300-301$ y 471; Tormo y Monzó, E., «Álbum de lo inédito para la Historia del Arte Español», B.S.E.E., 1916, pp. 225-229; Gómez Moreno, M., Las águilas de Renacimiento español, Madrid, 1983, $2^{\text {a }}$ ed., p. 159; Post, R.C., A History of Spanish Painting, Cambridge (Mass.), 1947, t. IX, part 2, pp. 697-703 (y 1966, t. XIII, pp. 228-230); Angulo Íñiguez, D., La pintura del siglo XVI, en Ars Hispania, Madrid, 1954, XII, pp. 120 y 189; Gudiol Ricart, J., «Un pintor manierista, Juan de Pereda», Il Vasari, 1963, pp. 81-84; Camón Aznar, J., La pintura española del siglo XvI, en Summa Artis, Madrid, 1970, XXIV, pp. 235-237; Ávila Padrón, A., 1979, pp. 136-145; «Juan Soreda, no Juan de Pereda. Noticias documentales e iconográficas», A.E.A., 1979, pp. 405-424; Buendía Muñoz, J.R., El Renacimiento, en Historia del Arte Hispánico, Madrid, 1980, III, pp. 239-241; Ávila Padrón, A., «Influencia de la estampa en la obra de Juan Soreda», Boletín M.I.C.A., 1981, pp. 81-93; Navarro Talegón, I., Pintura de Toro. Obras restauradas, Toro-Zamora, 1985, pp. 15 y 21; Díaz Padrón, M., «Tres tablas restituidas a importantes maestros de Tierra de Campos. Nicolás Francés, Fernando Gallego y Juan Sureda», Goya, 1987, 197, pp. 270-274; MARÍAS, F., El largo siglo xvı, Madrid, 1989, pp. 313-314; Ávila Padrón, A., Imágenes y símbolos, Barcelona, 1993, pp. 179-220; Padrón Mérida, A., «Una predela de Juan Soreda en el Museo Lázaro Galdiano», Goya, 1993, pp. 335-339; Mateo Gómez, I., La Pintura en España, en La pintura europea, Milán, 1995, I, p. 213; Nieto Alcaide, V.; Parrado del Olmo, J.M.; Brasas Egido, J.C., Renacimiento y clasicismo, en Historia del Arte en Castilla y León, Valladolid, 1996, V, p. 290; Ávila Padrón, A.; Buendía Muñoz, J.R., «La pintura», El siglo del Renacimiento, Madrid, 1998, pp. 216.

${ }^{4}$ Ana Ávila (1993, p. 29) y Aída Padrón (1993, pp. 335-339) fueron las primeras en señalar que había que adelantar la cronología inicial de Juan Soreda. 
ya en la primera década del siglo XVI, un pintor con marcada personalidad que conoce y utiliza el lenguaje que imponían en Castilla Pedro Berruguete, Juan de Borgoña o Santa Cruz. La importancia de Juan Soreda radica en la modernidad de sus fuentes de inspiración formal e iconográfica así como en la influencia que ejercerá en Castilla (desde Valladolid a Zamora, pasando por Soria y Segovia) e incluso en la zona occidental de Aragón.

Las primeras referencias biográficas sobre Soreda son las del desaparecido retablo de Sienes en $1506^{5}$ y dado que su muerte tuvo lugar en El Burgo de Osma a finales de 1536 o principios de $1537^{6}$, hay que valorar su figura y su arte como enlace entre la generación de Pedro Berruguete, Juan de Flandes y Pablo de San Leocadio y la formada por Alonso Berruguete, Pedro Machuca, Vicente Maçip y Pedro Fernández. Su producción ha de ser enjuiciada con relación a ese marco temporal, geográfico y conceptual impregnado - en sus más célebres representantes - de los ideales del tardocuatrocentismo y del pleno renacimiento italianos. Tal período fue muy breve dentro de la historia de la pintura española y particularmente fugaz a la vez que fecundo en la castellana ${ }^{7}$. En este sentido existe un claro paralelismo cronológico y estilístico entre el papel de Soreda en Sigüenza y El Burgo de Osma y el de Yáñez de la Almedina y Hernando de los Llanos en la pintura manchega y levantina de la época ${ }^{8}$.

En referencia a las tablas de Torremocha del Pinar hay que decir que las cuentas del Libro de fábrica de Luzón - transcritas al final- informan de que el entallador ${ }^{9}$ había concluido su labor en 1505. En 1507 se inician los pagos a Juan Soreda como pintor. Su trabajo se da por terminado en 1510 aunque el finiquito no se paga hasta 1512 a nombre de su oficial Pedro de la Puente. A este último se atribuye la tabla de la Circuncisión ${ }^{10}$ por comparación con sus obras documentadas en Pardos y Tordesilos (Guadalajara) y por el evidente descenso de calidad respecto a la de Soreda en las escenas estudiadas. Por tanto, hay que datar el grueso de la pintura del retablo entre 1508 y 1510, fechas en las que Soreda ya empleaba al citado oficial, venido seguramente desde Aragón ${ }^{11}$. No es aventurado pensar que la actividad de Soreda se iniciara antes de 1506, porque su estilo y la posesión de un taller compuesto por un ayudante así lo

\footnotetext{
${ }^{5}$ Obra desaparecida que finalmente fue contratada con el pintor seguntino Francisco de la Nestosa entre 1509 y 1512 (Arch. Histórico Diocesano de Sigüenza, Libro de quentas y aniversarios de Sienes, año 1506-1512, fols. 8-18). Algunos datos sobre el retablo de Sienes aparecieron en mi tesis de licenciatura: La pintura en la ciudad de Sigüenza y su jurisdicción, Guadalajara, 1998. En estos documentos se le cita junto al pintor de Guadalajara Hernando Rincón de Figueroa, autor del retablo mayor de la Colegiata de Medinaceli (Soria).

${ }^{6}$ Navarro Talegón, I., 1985, p. 15. A.H.P. de Zamora, Lope Gutierres (e.p. de Toro), Protocolo Notarial 3090, (25-VIII1537), fols. 332-332v. Hago notar que en los mismos años mueren Juan de Borgoña, Pedro de Aponte y Hernando Yáñez de la Almedina.

${ }^{7}$ Con posterioridad a 1525-1530, la pintura castellana deriva rápidamente hacia un estilo expresivo, dinámico y de canon figurativo estilizado que amalgama, en una síntesis extraña, elementos tomados del manierismo flamenco y del dúo Berruguete-Machuca, no sin corromper y degradar sus extraordinarios y personales vocabularios. Una situación semejante se vive en Valencia, en Cataluña y en las zonas marginales de Andalucía hasta el progresivo triunfo del estilo romanistacontrarreformista de Gaspar Becerra, Navarrete y los pintores de El Escorial.

${ }^{8}$ No quiero decir con ello que la trascendencia de la obra de Juan Soreda para la pintura española de la primera mitad del siglo xvi sea comparable a la de Yáñez de la Almedina, sino que su actividad tuvo unas consecuencias modernizadoras en Sigüenza, que influyeron notablemente en la evolución de la pintura posterior en el corazón de Castilla. Además la calidad estética y técnica del maestro de la Almedina es superior a la de Soreda.

${ }^{9}$ Obra escultórica de la cual no ha sobrevivido nada. Del entallador Gaspar no se conocen más datos que éste.

${ }^{10}$ Pintor documentado en Sigüenza y Molina de Aragón hasta 1544. Posee varias pinturas documentadas y otras atribuibles que daré a conocer en mi tesis doctoral. Pedro de la Puente también interviene en algunos elementos de la escena del Calvario, que por situarse en lo alto del retablo no se ejecuta con la misma precisión.

" En Tarazona se constata la presencia de una familia de pintores capitaneada por Juan y Prudencio de la Puente que se extiende hasta Zaragoza. Prudencio trabaja en la capital del Ebro, pero sobre todo en la catedral de Tarazona. Abizanda y Broto, M., Documentos para la historia literaria y artística de Aragón. Siglo Xvi, Zaragoza, 1915, I, pp. 251-252. Además se le atribuye un retablo en la antigua colección Weissberger de Madrid. Post, R.C., 1966, XIII, pp. 197-203; Camón Aznar, J., 1983 (2. ${ }^{a}$ ed.), XXIV, p. 293. Una de las tablas que formaban el retablo de San Miguel de Tarazona, Santo Obispo, aparece dentro del 'stand' de la empresa Peña y Rodríguez S.L., en el Catálogo de la I Exposición de Anticuarios de Madrid (Madrid, 1966, pp. 59-60).
}

$A E A, \mathrm{LXXV}, 2002,299$, pp. 293 a 334 
hacen suponer. Por tanto, es posible que existan pinturas de su mano datables hacia 1500, todavía sin documentar y cercanas estilísticamente al foco de miniaturistas y pintores del monasterio de La Espeja (Soria), comandado por el hasta hace poco tiempo denominado Maestro de Osma -identificado por J. Rogelio Buendía como fray Jerónimo de Espinosa - ${ }^{12}$. Siguiendo estos planteamientos cabría situar su nacimiento hacia 1475-1478.

Llegados a este punto se hace necesario explicar cómo llegaron a Torremocha del Pinar las cinco escenas procedentes de Luzón. En esta última villa se constatan tres retablos sucesivos en los siglos XVI al XVIII; el momento que ahora nos interesa es el de la sustitución del más antiguo por otro de 1653. En dicho año se recoge en Luzón una escueta referencia documental que dice: «Retablo: setecientos y dies maravedís que pagó a Francisco Vallejo, maestro de samblaje por quenta de ochenta ducados questá conzertada la obra del retablo». Ignoro si esta data corresponde a una reforma aplicada al retablo de Soreda y Gaspar o, por el contrario, se refiere a un altar de nueva traza; en cualquier caso, las pinturas de Soreda se pudieron reaprovechar en la nueva obra tasada en el módico precio de ochenta ducados ${ }^{13}$. Además, sabemos que la iglesia de Luzón costeó un nuevo sagrario hacia 1630, fecha que se acerca a la que aparece actualmente inscrita en el centro del retablo de Torremocha del Pinar (1637). No por casualidad, el altar que hoy luce en el presbiterio de la iglesia de Torremocha del Pinar se fecha a mediados del siglo XVII ${ }^{14}$. Si se tiene en cuenta que Torremocha del Pinar está a menos de treinta kilómetros de la villa de Luzón, todo induce a pensar que el retablo de Luzón de 1653 con las tablas añadidas de Soreda es el que hoy preside la parroquial de Torremocha del Pinar, a la que se trasladaría después de 1747 tras colocarse en Luzón un tercer altar, esta vez tardobarroco, para decorar el presbiterio de la recién ampliada iglesia ${ }^{15}$. El hecho de permanecer en buen estado de conservación contribuyó al traslado del retablo en compañía del sagrario de $1637^{16}$. Por otro lado, la intensa participación de Pedro de la Puente en una de las tablas concuerda con la citada referencia documental del Libro de cuentas de Luzón en 1512. Correspondan o no las tablas de Torremocha del Pinar al retablo documentado de Luzón (aunque todo hace pensar que sí), lo que resulta innegable es la autoría de Soreda en la Presentación en el Templo, Anunciación, Calvario y Visitación conservadas en Torremocha.

El primitivo retablo contenía varias escenas más de las cinco conservadas hoy en Torremocha, según se desprende de los más de cien mil maravedís cobrados por Soreda. Es evidente que el ciclo iconográfico compuesto por episodios de la vida de la Virgen (Presentación en el Templo, Visitación, Anunciación) y de la Infancia de Jesús (Circuncisión), se conserva incompleto; faltan escenas tan habituales como el Abrazo ante la Puerta Dorada, el Nacimiento de María, la Asunción, la Natividad, la Epifanía o la Presentación del Niño en el Templo. El Calvario no forma parte del ciclo narrativo propiamente dicho sino que es un reflejo de la extendida costumbre de culminar casi todos los retablos parroquiales del siglo XVI con ese tema.

\footnotetext{
${ }^{12}$ Buendía Muñoz, J.R., «Síntesis y puntualizaciones sobre el desarrollo del arte oxomense-soriano (1500-1790)», en I Semana de Estudios Históricos de la Diócesis de Osma-Soria, Soria, 1997, I, pp. 254-255.

${ }_{13}^{13}$ Marco Martínez, J.A., 1997, p. 487: cita el documento encontrado en el Libro de cuentas de Luzón.

${ }^{14}$ Según nos ha indicado personalmente Juan Antonio Marco Martínez, máximo especialista en los retablos barrocos de Guadalajara como autor de un amplio y documentado trabajo titulado: El retablo barroco en el antiguo obispado de Sigüen$z a$ (Guadalajara, 1997).

${ }^{15}$ El retablo de 1653 se habría quedado pequeño en el nuevo y ampliado presbiterio, por lo que se encargó un retablo mayor al entallador Francisco del Castillo por 5.750 reales. Marco Martínez, J.A., 1997, pp.487-490. En la zona es habitual la venta de retablos entre parroquias.

${ }^{16}$ Sagrario policromado por Baltasar de Hergueta y tallado por Juan de Pinilla hacia 1630. Véase: Marco Martínez, J.A., 1997, pp. 487-488
}

AEA, LXXV, 2002, 299, pp. 293 a 334 



Fig. 1. Juan Soreda. Presentación de la Virgen en el Templo. Torremocha del Pinar (Guadalajara). 1510.

Fig. 2. Juan Soreda. Visitación. Torremocha del Pinar (Guadalajara). 1510.

Fig. 3. Juan Soreda. Anunciación. Torremocha del Pinar (Guadalajara). 1510.

Fig. 4. Juan Soreda. Anunciación (detalle).

AEA, LXXV, 2002, 299, pp. 293 a 334 
Quiero señalar que todos los cuadros excepto el Calvario fueron recortados en el siglo xviI para amoldarse al tamaño de las calles laterales del nuevo altar ${ }^{17}$. Tal atentado contra la primitiva estructura de los paneles, en conjunción con los diversos cambios de ubicación, ha afectado irremediablemente a su cohesión. Si exceptuamos la Presentación de María en el Templo, el resto de los paneles presentan grietas y faltas de pintura en varias partes de la superficie. Es obligado señalar la necesidad urgente de una intervención que fije la pintura al soporte y que elimine las capas de suciedad.

En las cuatro pinturas analizadas a continuación se demuestra el temprano y profundo conocimiento de la obra de Juan de Borgoña ${ }^{18}$, quien por esos años estaba trabajando en el retablo mayor de la catedral de Ávila y en las escenas murales de la Sala Capitular de la catedral de Toledo. El mejor ejemplo de la citada influencia es la escena de la Presentación de María en el Templo ${ }^{19}$ [Fig. 1], inspirada directamente en la composición del mismo título para el retablo de Carboneras de Guadazón (Cuenca, Museo Diocesano) atribuida al taller de Juan de Borgoña y fechada hacia $1510^{20}$, aunque lo dicho hace pensar que podría ser unos años anterior. La concepción del paisaje tampoco está demasiado alejada de la utilizada por Juan de Borgoña en ese momento.

Por otro lado, en la tabla del Calvario [Fig. 5] el tipo de cruz coincide con el usado por Juan de Borgoña en el retablo de la Epifanía de la catedral de Toledo (c. 1514). Soreda retomará esta tipología en el retablo de Santa Librada y sus seguidores seguntinos la mantendrán durante largo tiempo. Sin embargo, en el sentido volumétrico de las vestiduras y de los rostros, Soreda reduce el habitual flamenquismo que subyace en Juan de Borgoña, mediante ciertas notas hispanas e italianizantes que no dejará de desarrollar en su obra posterior, notas que le alejarán progresivamente de Borgoña y de los pintores toledanos de su círculo. La Visitación [Fig. 2] también presenta puntos en común con la obra de Juan de Borgoña en lo compositivo. Iconográficamente destaca el muro de fondo que ubica el desarrollo de la escena en el interior de la vivienda de María, concebida como 'hortus conclusus', como también aparece en otras obras de Sigüenza (retablo mural de la ermita de Nuestra Señora de los Huertos). Las doncellas del fondo son figuras típicamente soredianas, tanto por su diseño como por el colorido de los ropajes y sobre todo por el humanismo de su actitud dialogante.

Respecto a Pedro Berruguete, Soreda parece conocer sobre todo las obras abulenses, donde las figuras adquieren un mayor sentido volumétrico. Así, la figura de San Joaquín de la Presentación de María en el Templo [Fig. 1] de Torremocha del Pinar, está inspirada directamente en un personaje de la escena de Santo Domingo resucitando a un niño (Museo del Pra-

\footnotetext{
${ }^{17}$ Medidas actuales: $48,5 \times 95 \mathrm{~cm}$. (excepto la Visitación: $49 \times 96,5 \mathrm{~cm}$.). No pude medir el Calvario debido a su posición elevada, si bien la medida vertical rondará los $95 \mathrm{~cm}$. Incluso en la escena de la Circuncisión hay un añadido de una escena diferente en la que se ve el cortinaje de una cama, una portada de piedra y un brazo.

${ }^{18}$ El origen toledano del estilo de Soreda ha sido referido por Fernando Marías (1989, pp. 313-314). Ana Ávila (1979, p. 136) ha señalado que «participa del canon de maestros que trabajan en la península, como Juan de Borgoña, con quien se ha establecido una relación estilística y de escuela». En su relación con el ambiente toledano, Soreda coincide con el otro gran pintor alcarreño del momento, Hernando Rincón de Figueroa, quien se había llevado el contrato del retablo mayor de Santa María de Medinaceli (Soria), la gran obra pictórica del Obispado seguntino a principios de la decimosexta centuria. Respecto a la controvertida figura de Rincón véase mi libro La pintura en la ciudad de Guadalajara y su Jurisdicción (1500-1580), Guadalajara, 1998, pp. 74-117.

${ }^{19}$ En esta escena toma de Juan de Borgoña el característico tono brillante del manto rojizo de la Virgen Niña. Por otra parte, el rostro del Sumo Sacerdote que recibe a María es idéntico tipológica y estilísticamente al que aparece en la Presentación de Jesús en el Templo (Soria, concatedral de San Pedro), lo que hace más segura la atribución a Soreda de las tablas de Torremocha del Campo y paralelamente de la Presentación de Soria.

${ }^{20}$ Ibáñez Martínez, P.M., La pintura conquense del siglo XVI, 1993, I, pp. 167-179. El profesor Ibáñez también señala la conexión entre las obras tempranas de Soreda y el estilo de Juan de Borgoña (p. 176). Las figuras de San Joaquín y Santa Ana están tomadas directamente de otra tabla de la escuela de Juan de Borgoña en la capilla de San Roque de la catedral de Cuenca, publicada por Post (1950, X, 402-405, fig. 167).
} 

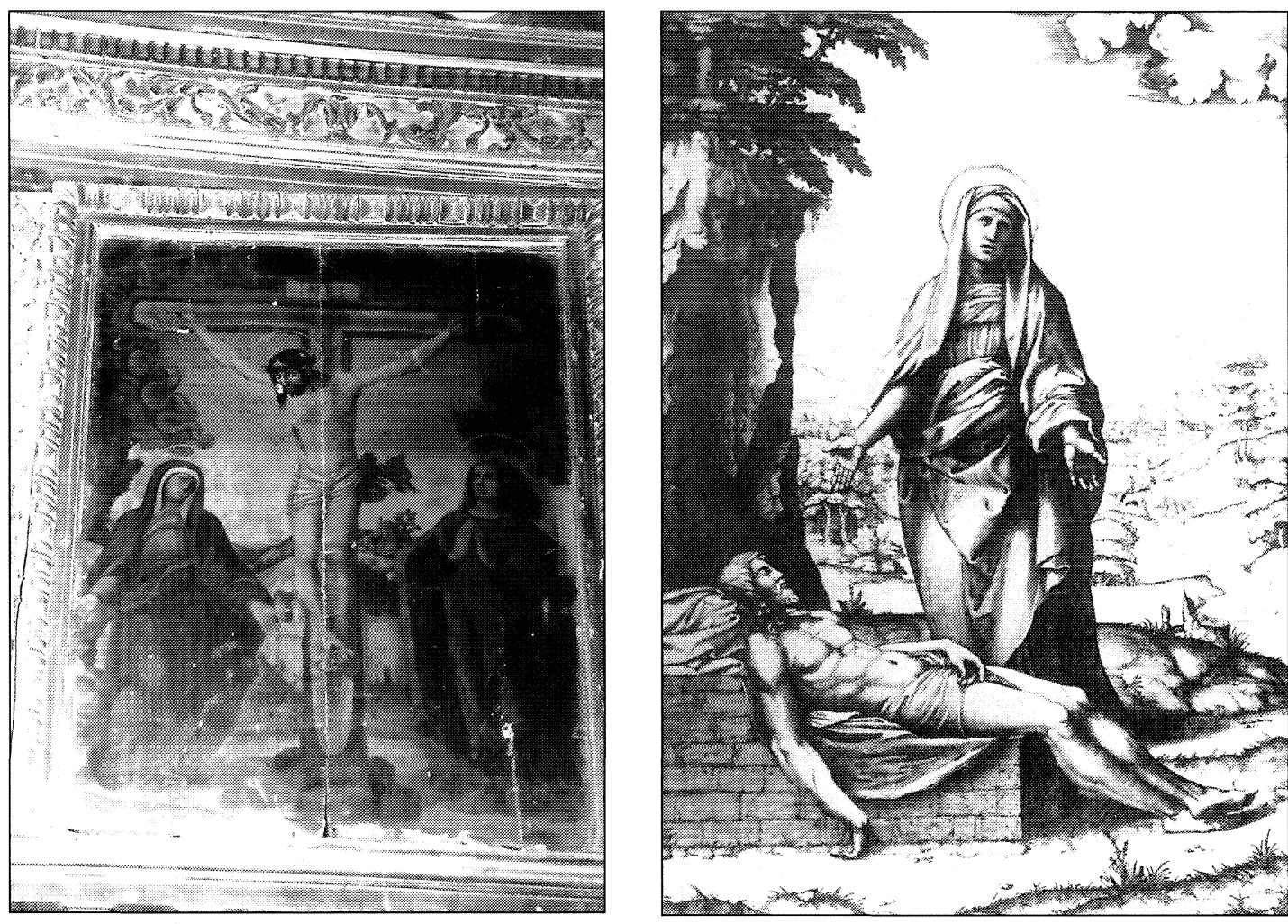

Fig. 5. Juan Soreda. Calvario. Torremocha del Pinar (Guadalajara). 1511-1512.

Fig. 6. Marcantonio Raimondi. Lamentación de la Virgen. 1511.

do), pintada por el maestro palentino para el convento de Santo Tomás de Ávila (1490-1496) ${ }^{21}$. Soreda únicamente le ha cambiado la indumentaria.

A lo largo de las cuatro escenas atribuidas a Juan Soreda se aprecian numerosos aspectos formales propios de lo que será su lenguaje posterior. Entre ellos cabe destacar el gusto por los tonos azulados muy tenues, el sentido intimista de los rostros, la dulzura de sus ángeles y Vírgenes juveniles y el uso de estampas rafaelescas. La contención expresiva de sus obras iniciales se transformará, de un modo progresivo, en la tensa crispación del retablo de Olivares de Duero. El mayor grado de ternura y delicadeza se alcanza en la escena de la Anunciación [Fig. 3], con una ventana renacentista abierta a un delicioso paisaje de fondo. Las arquitecturas de fondo todavía no están decoradas con escenas mitológicas, no tienen el sentido parlante de los retablos de Santa Librada y Olivares de Duero ${ }^{22}$ pero ya se acercan al vocabulario característico del lenguaje renacentista. Otro recurso que nos indica el arcaísmo de estas tablas

\footnotetext{
${ }^{21}$ Véase la cronología propuesta por Víctor Nieto Alcaide (Pedro Berruguete, Madrid, 1988, p. 91, fig. 37) y más recientemente por Pilar Silva Maroto (Valladolid, 1998).

${ }^{22}$ La bibliografía del retablo de Olivares de Duero es la que sigue: Martí Monsó, J., «Retablos de Quintanilla y Olivares», B.S.E.E., 1903, I, p. 314; Martín González, J.J., «El retablo de Olivares de Duero», B.S.A.A., XX, 1953-1954, pp. 31 42; Gudiol Ricart, J., 1963, pp. 81-83; Ávila Padrón, A., 1979, pp. 141-144; Ávila Padrón, A., «Influencia de la estampa en la obra de Juan Soreda», B.M.I.C.A., 1981, pp. 81-93. Martín González, J.J., «El retablo», Catálogo de la Exposición de la Restauración del retablo mayor de la iglesia parroquial de Olivares de Duero, Valladolid, 1986; Martín González, J.J., «Actualidad del retablo de Olivares de Duero», B.S.A.A., LIII, 1987, pp. 372-374. Parrado del Olmo, J.M., «Pedro de Guadalupe y Alonso de Berruguete en el retablo mayor de Olivares de Duero (Valladolid)», B.S.A.A., 1987, pp. 372-373. Nieto Alcaide, V.; Parrado del Olmo, J.M.; Brasas Egido, J.C. y otros, 1996, V, p. 290; Parrado del Olmo, J.M., «Juan Soreda. Tortura de San Pelayo», en Catálogo de la Exposición Vlaanderen en Castilla y León, Amberes, 1995, pp. 498-499.
}

AEA, LXXV, 2002, 299, pp. 293 a 334 
es la utilización de nimbos dorados, elemento que repetirá escasamente en su obra posterior ${ }^{23}$. Algo similar ocurre con el canon achaparrado de las figuras y con la perspectiva gotizante de la Anunciación [Fig. 3]; ambos elementos evolucionarán lentamente hacia una mayor modernización en sus producciones de los años veinte y treinta.

Es de admirar el temprano conocimiento de la estampa de la Virgen ante el cuerpo muerto de Jesús de Marcantanio Raimondi [Fig. 6], ejecutada a partir de un diseño de Rafael conservado en el Museo del Louvre ${ }^{24}$. Soreda se inspira directamente en ella para su Virgen doliente del Calvario [Fig. 5]. Es interesante volver nuestra atención al estudio de este modelo, pues no hay acuerdo entre los diversos autores acerca de su datación. No cabe duda de que el origen del grabado está en un dibujo que representa el mismo tema, del que se conservan dos versiones, una en el Louvre y otra muy similar en el Ashmolean Museum de Oxford. Para algunos autores el diseño del Louvre es original de Rafael y lo datan en $1511^{25}$; según Joannides y Oberhuber su autor podría ser Giovan Francesco Penni, no obstante lo cual, Davidson lo considera de mano de Perin del Vaga y en el último libro de Knab-Mitsch-Oberhuber se da como del propio Rafael ${ }^{26}$. Yo pienso que el dibujo - sea quien sea su autor- hubo de realizarse antes de 1511, porque el grabado que nace de él se conoce en España ese mismo año y porque también lo utilizan muy pronto otros pintores italianos como Paris Bordone. Según el propio Joannides, el dibujo más antiguo de los dos sería el conservado en Oxford (1506-1507), lo cual me parece más acertado ${ }^{27}$.

Si los dibujos pueden fecharse a finales de la primera década del siglo, no ocurre lo mismo con el grabado, ya que Raimondi no colaboró con Rafael antes de $1510^{28}$. Por tanto, tuvo que ser uno de sus primeros trabajos en común, como lo demuestra el hecho de que la mayoría de los estudiosos del grabado rafaelesco proponen la fecha de $1511^{29}$ — Shoemaker es el único que apunta la de 1512 - . La conclusión de todo ello es que la utilización de la estampa por parte de Soreda es prácticamente instantánea, y aún así, nos vemos obligados a retrasar la conclusión de la tabla del Calvario de Torremocha del Pinar hasta 1511, un año después que el resto del retablo, lo que por otro lado parece insinuarse en la propia documentación de 1510: «... e mando al pintor que acabe de poner los guardapolvos e las otras cosas que faltan del retablo». En definitiva, ¿qué se deduce de todo lo dicho? Fundamentalmente que Soreda tuvo estrechos contactos desde joven con algún proveedor de material gráfico procedente de Italia ${ }^{30}$,

\footnotetext{
${ }^{23}$ El uso del jaspe en columnas y en otros elementos de sus fondos arquitectónicos, que ya se inicia en esta obra y pervivirá en su producción posterior, puede inspirarse igualmente en la Presentación en el templo de Carboneras de Guadazón (Cuenca, Museo Diocesano) o en otras obras de Juan de Borgoña; así como en las cercanas canteras de mármol de Espejón, según me ha sugerido personalmente el profesor Buendía.

${ }^{24}$ Bartsch, A. von, The Illustrated Bartsch. Italian Masters of the Sixteenth Century (Commentary), New York, 1995, 28, vol. 15 (part 1), pp. 265-269. Ana Ávila ya señaló la utilización de este grabado con relación al Calvario del retablo de la Vida de Santa Librada (Sigüenza, catedral), de 1526.

${ }^{25}$ Bernini Pezzini, G.; Massari, S.; Prosper Valenti, S., Raphael Invenit. Stampe da Raphaello nelle collezioni dell'Istituto Nazionale per la Grafica, Roma, 1985, p. 173.

${ }^{26}$ Joannides, P., The Drawings of Raphael with a Complete Catalogue, Oxford, 1983, p. 212. Knab, E.; Mitsch, E.; Oberhuber, K., Raffaello. I Disegni, Florencia, 1984, p. 616.

${ }^{27}$ Joannides, P., 1983, pp. 163, 212. Existen apuntes en el Ashmolean Museum, en el reverso de dos dibujos datados entre 1506 y 1507, en los que aparece aislada y fragmentada la figura de Cristo muerto siguiendo la misma traza que en el grabado de Raimondi, lo que parece indicar la realización del diseño originario de Rafael en esos años (pero falta todavía la figura de la Virgen doliente). Los contornos están punteados como si hubieran servido para trasladarse a otra superficie.

28 Tomado de: González de Zárate, J.M., Artistas grabadores en la Edad del Humanismo, Pamplona, 1999, pp. 119-121. También cabe la posibilidad, aunque remota, de que la estampa sea anterior a 1510, si nos atenemos a la hipótesis planteada por Popham y Wilde de que el dibujo del Louvre fuese una copia del taller de Rafael realizada a partir del grabado de Raimondi, el cual a su vez se inspiraba en un diseño perdido del maestro de Urbino. Tal posibilidad parece aventurada.

${ }^{29}$ Bernini Pezzini, G.; Massari, S.; Prosper Valenti, S., 1985, p. 173; Oberhuber, K., 1984, p. 334

${ }^{30}$ Los grabados circulaban por Europa con gran rapidez, sobre todo a través de comerciantes y eclesiásticos. Soreda debió formar su nutrida colección - que luego heredará Luis del Castillo- en las catedrales de Sigüenza y El Burgo de Osma o en monasterios como La Espeja (Soria).
} 
ya que tal grado de contemporaneidad en el manejo de fuentes extranjeras no se entiende de otra manera. Pese a ello, esos avances se combinan con elementos arcaizantes como las rígidas nubes de los laterales, en las que se aprecia la mano de su colaborador Pedro de la Puente.

En la Anunciación, el sentido sosegado y armonioso que confiere a María [fig. 4] recuerda poderosamente al de la Virgen con el Niño del Museo Diocesano de El Burgo de Osma, obra también considerada de la primera época de Soreda, e incluso en mayor medida a la tabla del mismo tema del Museo de Dijon ${ }^{31}$.

En conclusión, el estilo temprano de Soreda germina a partir de modelos cuatrocentistas italianos (tomados fundamentalmente de la estampa), de Juan de Borgoña y de Pedro Berruguete, lo que demuestra una estancia temprana en Toledo o Ávila. En este momento todavía no se han impuesto en su obra los ecos de Leonardo, de Rafael y menos todavía de Miguel Ángel. Esta realidad se aprecia en el luminoso colorido, en el claroscuro de los ropajes y en las carnaciones poco contrastadas. Su evolución en los años posteriores será constante y notable, lo que se hace patente al comparar las piezas de Torremocha del Pinar con sus tablas de Olivares de Duero (por ejemplo el Martirio de San Pelayo, 1532-5). La transición entre ambas fases está representada fundamentalmente por el famoso retablo de Santa Librada de la catedral de Sigüenza (1526).

F. JAVIER RAMOS GómEZ

\section{APÉNDICE DOCUMENTAL:}

Archivo Histórico Diocesano de Sigüenza, Cuentas de Fábrica de la iglesia de Luzón, años 1505-1512, s.f.:

Año 1505: «E asy mismo se falló fecho de talla blanca un retablo ... gastó la talla treze mill maravedís ... mandaba e mandó que se acabe el dicho retablo de pintura e dorar por alguno singular pintor ... "

Año 1507: «Pintor: cinco mill seiscientos y sesenta e un maravedís que tiene dados a Soreda, pintor, $e$ con otros maravedís que dio gastados.»

Año 1508: «A Gaspar entallador, dos mill maravedís. A Soreda, pintor, tres mill y quinientos y sesenta maravedís. Fallose que tiene dados a Soreda, pintor, en dos veces ocho mill e setecientos y cinquenta y cinco maravedís.»

Año 1509: «Pintor: quatrocientos y setenta y ocho maravedís. Tres mill e quinientos y quarenta maravedís.»

Año 1510: «Soreda retablo: e fallo acabado e asentado el retablo, e mando al pintor que acabe de poner los guardapolvos e las otras cosas que faltan en el retablo. Pintor, ciento e treinta y siete maravedís.»

Año 1512: "Ciento e çinco mill y trezientos y quarenta y quatro maravedís que después della dio a Juan Soreda, pintor, e por su mandado a Pedro de la Puente, su oficial, para en quenta de lo que ovró del retablo...»

\section{PÉREZ VILLAAMIL EN INGLATERRA}

La posible estancia de Jenaro Pérez Villaamil en Gran Bretaña ha sido una tentadora sugerencia para algunos investigadores que, como Xavier de Salas, buscaban más indicios y razones al influjo británico de su pintura que el meramente aportado por su conocimiento del pintor escocés David Roberts. No es que este influjo fuese insuficiente, pero puede extrañar la

${ }^{31}$ Atribuida por Buendía Muñoz: El Renacimiento, en Historia del Arte Hispánico, Madrid, 1980, III, p. 240.

AEA, LXXV, 2002, 299, pp. 293 a 334 